\title{
PROGRESSIVE COLLAPSE ASSESSMENT OF PRECAST CONCRETE CONNECTIONS USING THE APPLIED ELEMENT METHOD (AEM)
}

\author{
M. EHAB ${ }^{1}$, H. SALEM ${ }^{2} \&$ M. ABDEL-MOOTY ${ }^{2}$ \\ ${ }^{1}$ Departement of civil Engineering, British University in Egypt. \\ ${ }^{2}$ Faculty of Engineering, Cairo University, Egypt
}

\begin{abstract}
Precast concrete components are manufactured in a well-controlled environment. It has been proven to show good behaviour under gravity and lateral loads. However, the beam to column connections remain the critical part in the precast concrete structures under the column loss scenario in a progressive collapse scenario. In this paper, different beam to column connections, wet and dry connections, are studied and investigated numerically under the column removal scenario. A detailed model for the different connections is developed using the Applied Element Method (AEM). Different column removal locations are considered in the study to provide a comprehensive assessment. The performance of the connections is studied in terms of ultimate load capacity and rotational ductility. According to the results obtained, a connection enhancement is suggested to increase the resistance of precast concrete structures to progressive collapse.
\end{abstract}

Keywords: Applied Element Method, precast concrete connections, progressive collapse analysis, RC corbels, special moment frames.

\section{INTRODUCTION}

In the last few decades, many precast concrete structures encountered total collapse due to accidental events of some structural elements. Ronan point failure took place in 1968 due to a gas explosion. The propagation of failure of the structure due to the local damage of one of the main structural components or its connection is defined as the progressive collapse.

Few researchers studied the overall behaviour of the precast concrete structure due to column loss scenario. Shi [1] evaluated the threat due to bombing and the progressive collapse of a prototype moment frame precast concrete building designed according to the PCI-seismic design Handbook. The effect of the column removal on the different beams has been investigated and suggestions for enhancing the beam resistance due to column removal has been proposed.

Main et al. [2] conducted a study on both full scale testing and detailed Finite element modelling of a precast concrete moment frame assembly of a 10-story prototype building where failure modes were recorded. Nimse et al. [3,4] studied different reduced one-third scaled precast wet and dry connections due to column removal. Failure mode and pattern for the studied connections were monitored and their resistance due to column removal were reported.

This current study focuses on the behaviour of two different types of connections under column removal scenario, ordinary and special moment frame beam to columns connections. They are picked from a 5-storey prototype precast concrete structure designed according to the ACI recommendations [5]. Different column removal locations were investigated. The 
connection modelling and analysis are conducted using a non-linear Applied Element Method (AEM) software called Extreme Loading of Structures (ELS), Meguro [6], Salem [7]. The behaviour is evaluated in terms of adjoining elements rotation, deflection, axial forces and steel reinforcement normal stresses variation with respect to time.

\section{APPLIED ELEMENT METHOD [8]}

The Applied Element Method is an innovative modeling method adopting the concept of discrete cracking, Tagel-Din and Meguro [9-11]. In Applied Element Method (AEM), the structures are modeled as an assembly of relatively small elements, made by dividing of the structure virtually, as shown in Fig. 1a. The elements are connected together along their surfaces through a set of normal and shear springs. The springs are responsible for the transfer of normal and shear stresses, respectively, from one element to another. Springs represent stresses and deformations of a certain volume as shown in Fig. $1 \mathrm{~b}$.

Each single element has six degrees of freedom; 3 for translations and 3 for rotations. Relative translational or rotational motion between two neighboring elements cause stresses

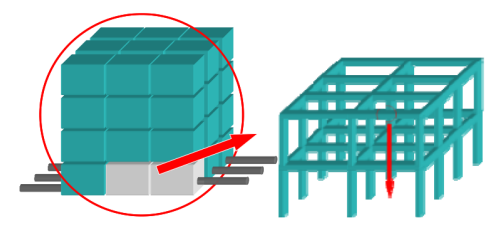

a- Element Generation for AEM

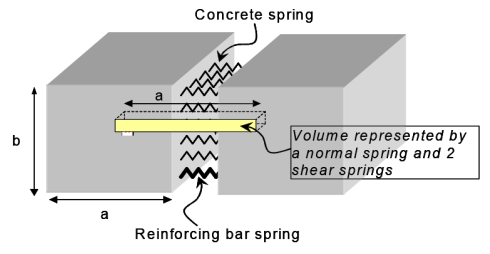

b- Spring distribution and area of influence of each pair of springs

Figure 1: Modeling of structure to AEM.

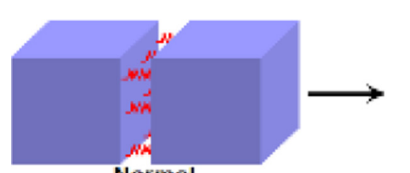

Normal

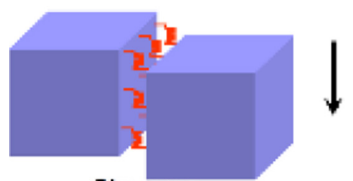

Shear $x-z$

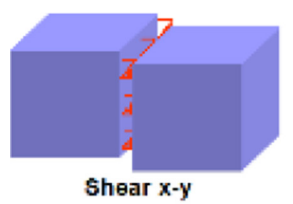

Relative translations

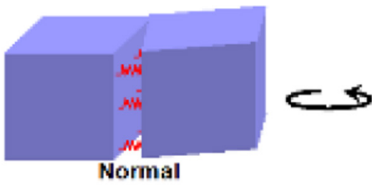

Normal

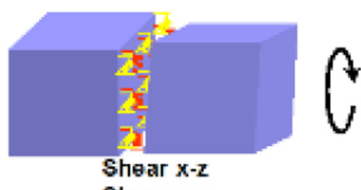

Shear $x-y$

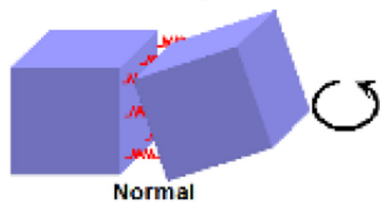

Relative rotations

Figure 2: Stresses in springs due to relative displacements. 


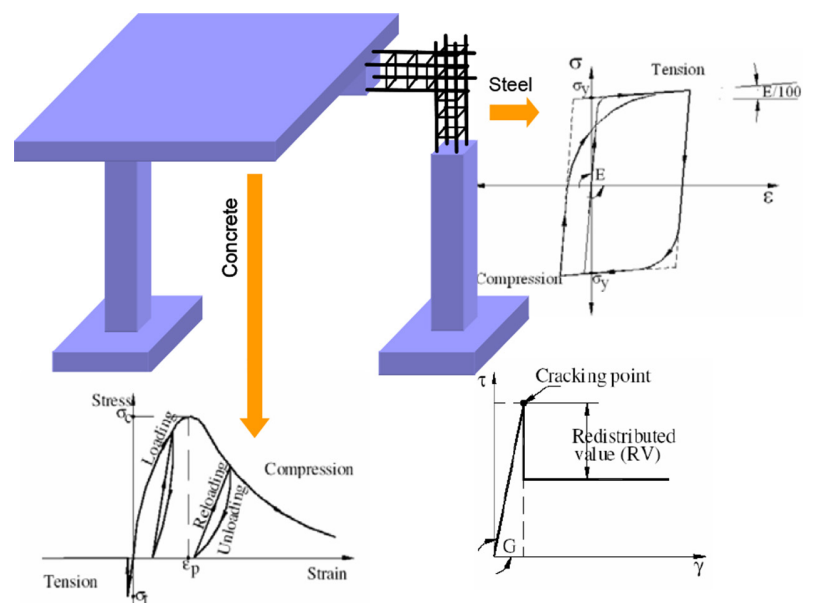

Figure 3: Constitutive models adopted in AEM for concrete and steel.

in the springs located at their common face as shown in Fig. 2. These connecting springs represent stresses, strains and connectivity between elements. Two neighboring elements can be separated once the springs connecting them are ruptured.

Fully nonlinear path-dependent constitutive models for reinforced concrete are adopted in the AEM as shown in Fig. 3. For concrete in compression, an elasto-plastic and fracture model is adopted, Maekawa and Okamura [12]. When concrete is subjected to tension, a linear stress-strain relationship is adopted until cracking of the concrete springs, where the stresses then drop to zero. The residual stresses are then redistributed in the next loading step by applying the redistributed force values in the reverse direction. For concrete springs, the relationship between shear stress and shear strain is assumed to remain linear till the cracking of concrete. Then, the shear stresses drop down as shown in Fig. 3. The level of drop of shear stresses depends on the aggregate interlock and friction at the crack surface. For reinforcement springs, the model presented by Ristic et al. [13]. The tangent stiffness of reinforcement is calculated based on the strain from the reinforcement spring, loading status (either loading or unloading) and the previous history of steel spring which controls the Bauschinger's effect. The solution for the dynamic problem adopts implicit step-by-step integration (Newmark-beta) method Bathe [14] and Chopra [15]. Separated elements may collide with other elements. In that case, new springs are generated at the contact points of the collided elements.

\section{THE PROGRAM VALIDATION}

In this section, the ELS software is validated by analyzing the specimens tested by Nimse et al. [4].

\subsection{Specimen description and modelling}

Three one-third scaled specimens are modelled and detailed using the ELS. The tested specimens are identified as monolithic connection (MC), precast connection of PC-CRW and PC-CRS, respectively. The detailing of the tested specimens as well as the ELS models are shown in Fig. 4. 

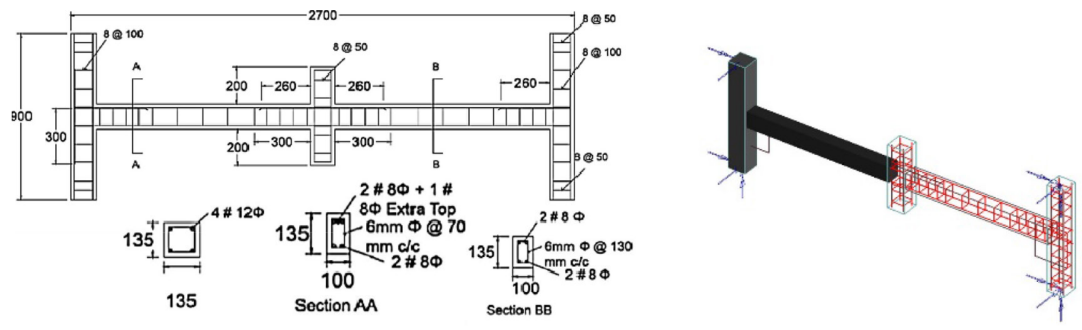

a- Monolithic Specimen

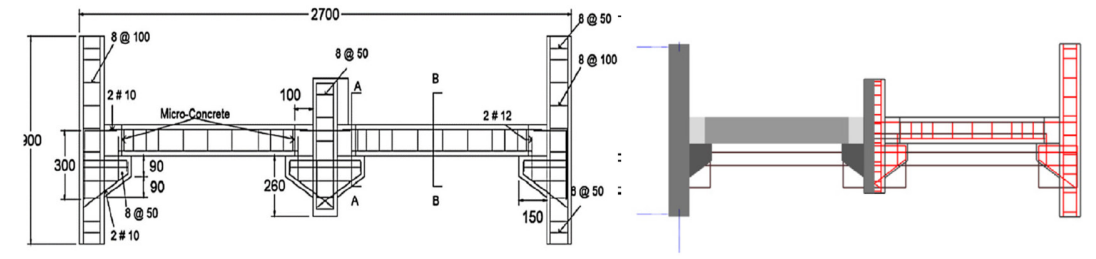

b- PC-CRW Specimen

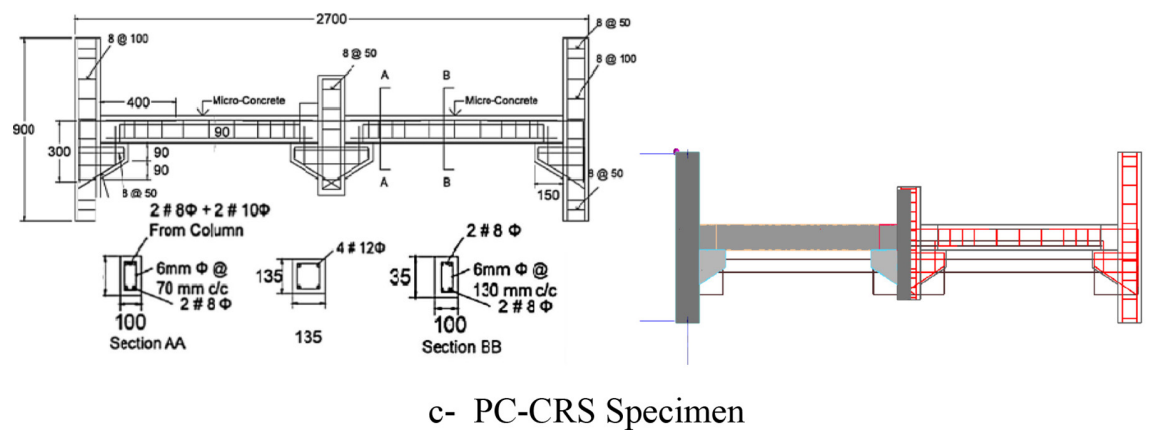

Figure 4: Specimen detailing and corresponding ELS models.

\subsection{Analysis of results}

Central deflection versus the applied load is shown in Fig. 5. The analytical model shows acceptable results compared to the experimental results.

\section{CASE STUDY}

A five-storey prototype precast structure with $3.5 \mathrm{~m}$ floor height is designed according to the ACI and PCI [16]. Two systems are considered: an ordinary frame system that resists only gravity loads; and a special moment resisting frames that resists lateral loading assuming the structure is in moderate seismic zone.

\subsection{Prototype structure description}

The floor consists of hollow core slabs with no concrete topping, L- beams placed at the structure perimeter and inverted T-beam used for the intermediate beams. Concrete compressive strength is $40 \mathrm{MPa}$ and the reinforcement steel yield strength is $420 \mathrm{MPa}$. 

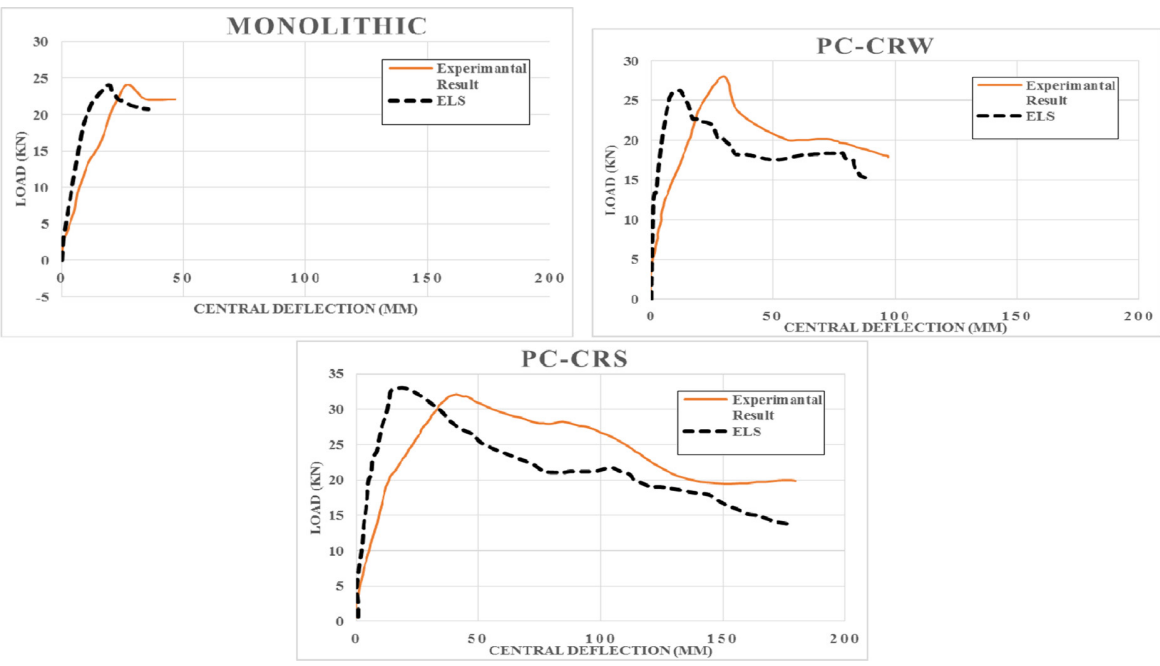

Figure 5: Load versus central deflection.

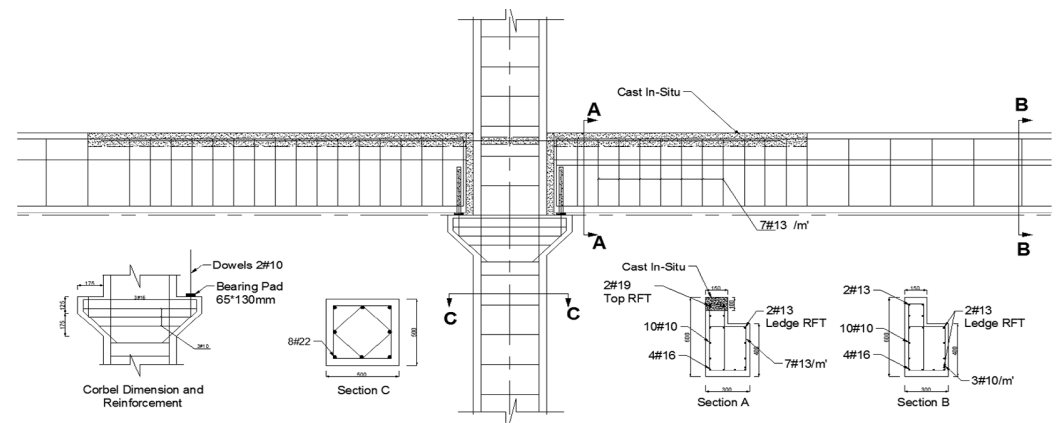

Figure 6: Ordinary moment frame connection (OMC).

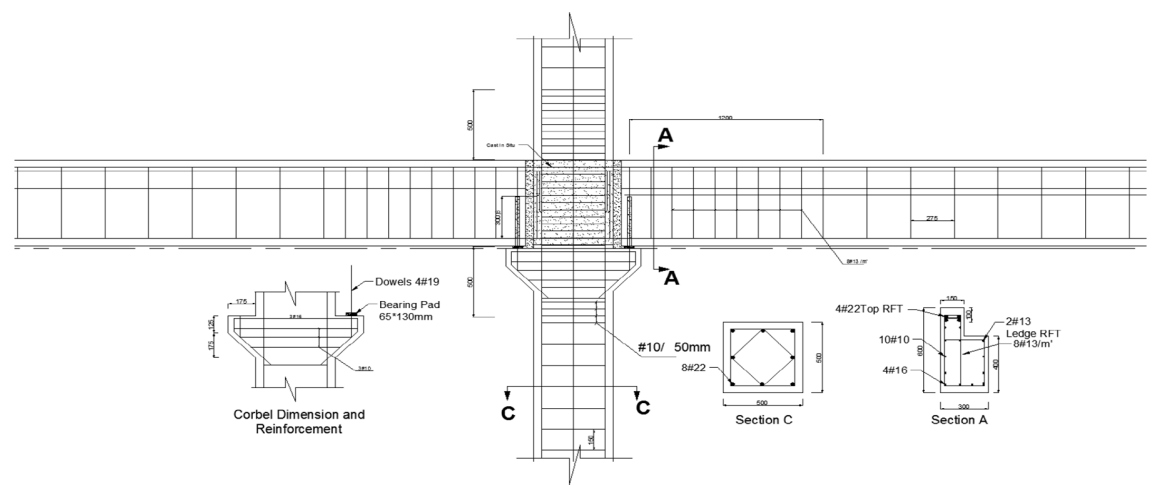

Figure 7: Special moment frame connection (SMC). 


\subsection{Beam to column connections}

$\mathrm{RC}$ corbel beam to column connection is adopted with two reinforcement detailing as shown in Fig. 7. For the ordinary moment frames, all beams and columns are designed under gravity loading. A $100 \mathrm{~mm}$ at the beam top is kept open with holes in the column for the addition of the top reinforcement. Cast in situ concrete is used for filling the gaps and the opening in columns and beams.

For the special moment frames a ductile design is adopted with strong-column weak-beam behaviour. The required top reinforcement of pre-cast beams with extended length is taken into consideration to be developed and inserted in the column gap, which is filled with cast in situ concrete as shown in Fig. 7.

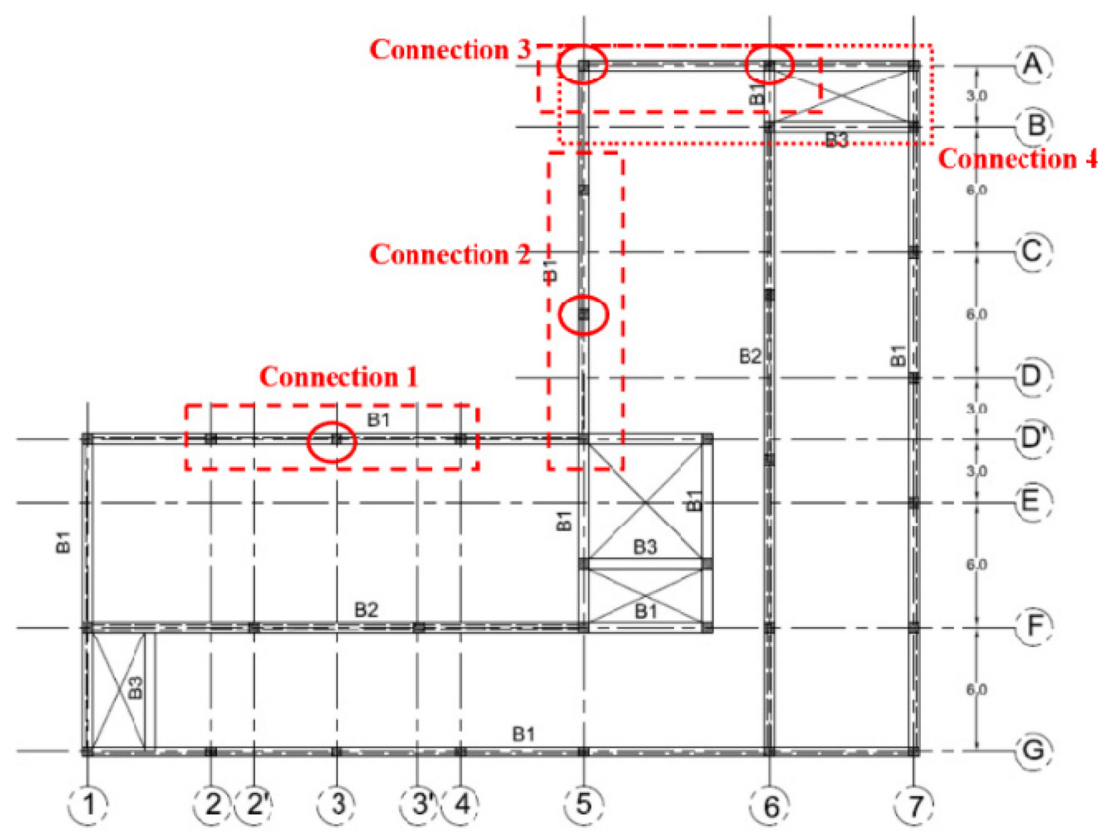

Figure 8: Prototype structural plan with the column removal scenarios.

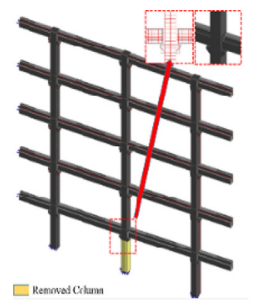

Connection 1

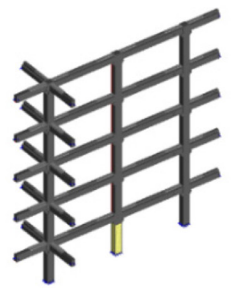

Connection 2

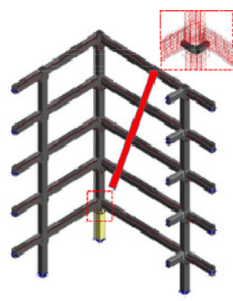

Connection 3

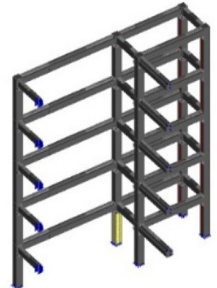

Connection 4

Figure 9: ELS models for the studied connections. 


\subsubsection{The analytical modelling}

Edge and exterior column's removal is presented in this study as shown in Fig. 8. The slab loads are applied directly on the precast beam without taking the slab model into consideration. A detailed modeling of the steel reinforcing bars and concrete with the selected material properties are defined in the ELS environment. The ground floor columns are assumed fixed to foundation. Appropriate boundary conditions are considered for beams that are not directly connected to the joint of concern where translational motion in the beam direction is prevented.

Dynamic analysis is carried out with a demolition scenario of the selected column over a time duration of 1 second with a time step of 0.001 seconds. Connection 1 is an in-plane connection connecting two $6 \mathrm{~m}$ span beam with L- shape cross section. Connections 2 is same as connection 1 except that one of the beam's ends is connected out of plane with $\mathrm{L}$ and rectangular cross section beams. Connection 3 is a corner connection connecting two $6 \mathrm{~m}$ and $9 \mathrm{~m}$ span beams perpendicular on each other. Connection 4 is connecting two $6 \mathrm{~m}$ and $9 \mathrm{~m}$ span L-beams in plane and one rectangular beam of $3 \mathrm{~m}$ span out of plane.

\subsubsection{Numerical results}

For the main structural elements, deflection, rotation and the axial forces of beams as well as the axial forces in columns are obtained. For the stresses in dowels connecting beams to RC and the top reinforcement are calculated.

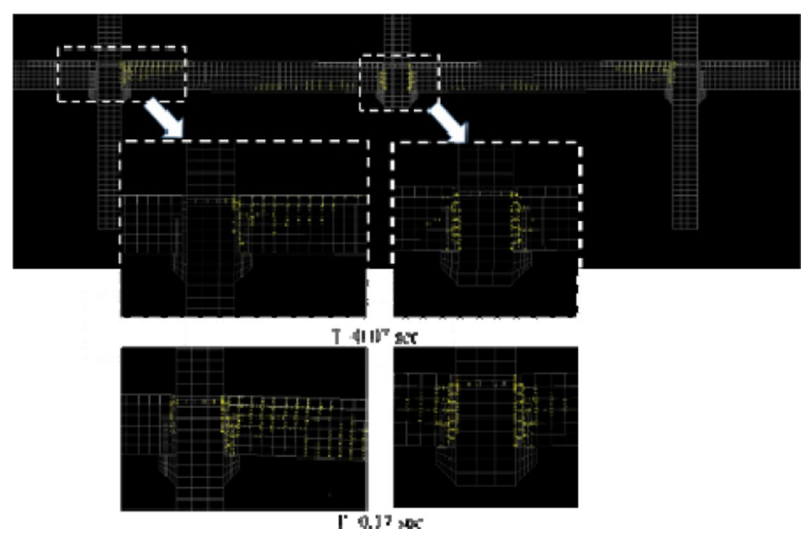

Figure 10: Crack propagation.
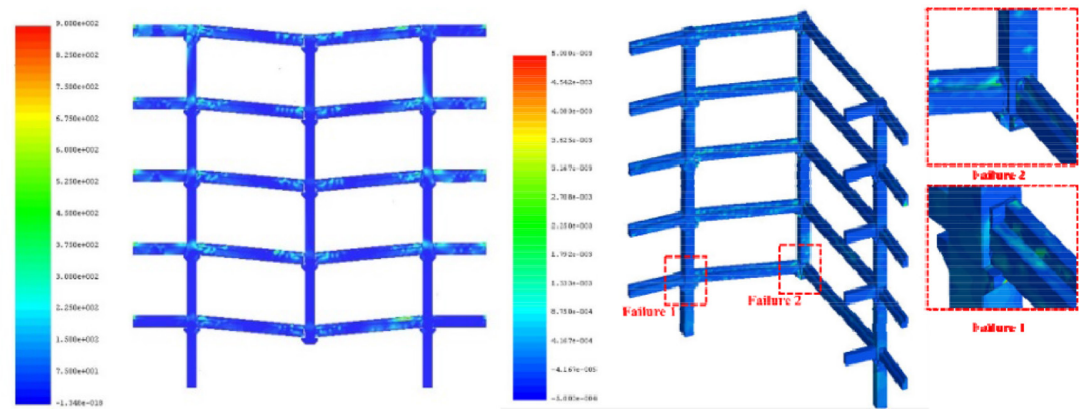

Figure 11: Stress contours for connection 1 (OMC) and connection 3 (SMC). 
Total collapse is reported for the ordinary moment connections and special moment connection except in connection 4. Crack initiation and failure started at the connections at the other end of the beam away from the removed column as shown in Fig. 10, cracks are indicated by yellow springs. The dowels and the top reinforcement of the other beam end fractured earlier than the dowels and the top reinforcement at the removed column connection. Stress contours for connection 1 and 3 are shown in Fig. 11.

4.2.2.1 Beam deflection and rotation. The maximum deflection for connection 1, 2, 3 and 4 in OMC are $-1500,-1550,-311$ and $-0.55 \mathrm{~mm}$, respectively, as shown in Fig. 12. The max-
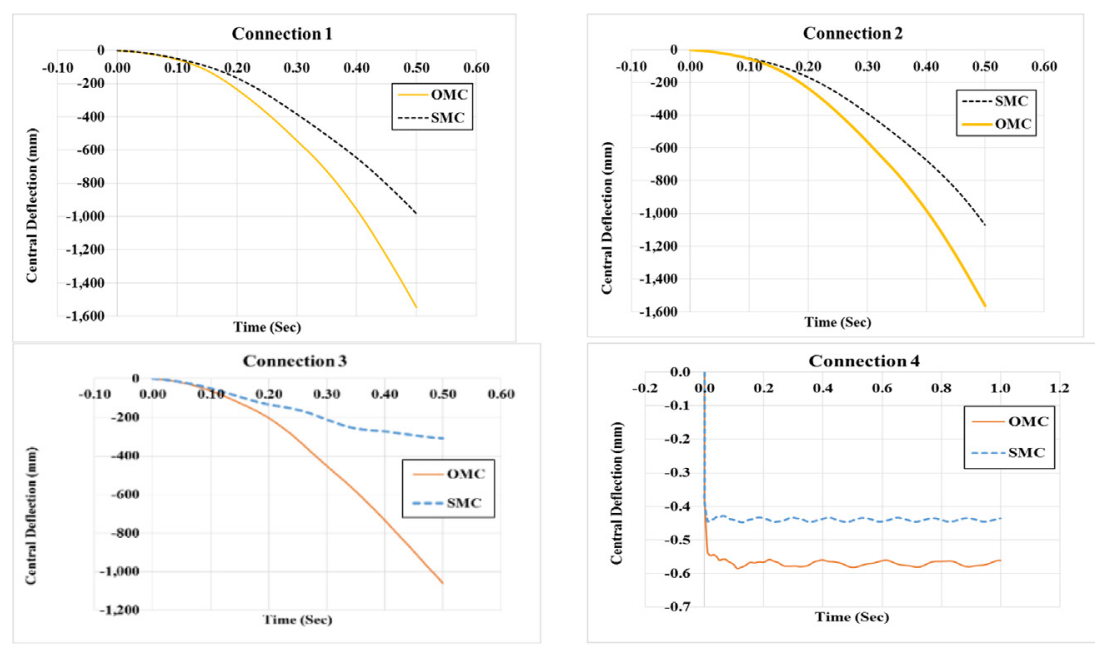

Figure 12: Beam deflection versus time.
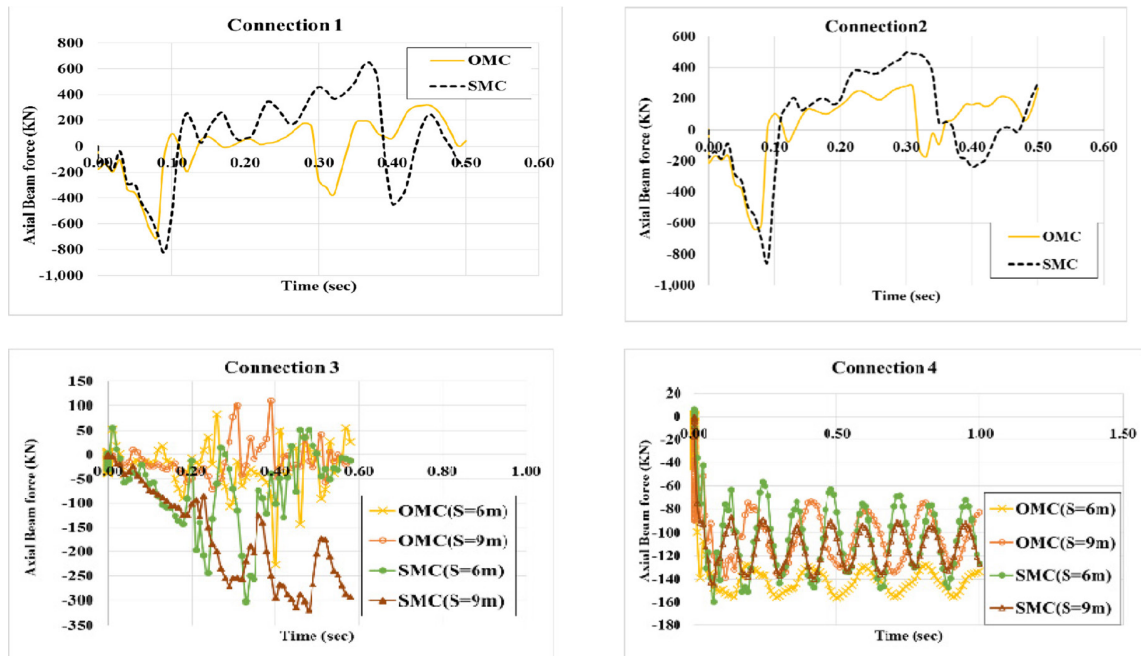

Figure 13: Beam axial force versus time. 
imum beam rotation for the $\mathrm{OMC}$ is 0.23 degrees for beam in connection 3 and for SMC is 0.049 degrees for beam in connection 3 .

4.2.2.2 Beam axial force. The compression arching effect is recognized in connection 1 and 2 in beams of OMC and SMC due to the confinement effect of in-plane beams and columns, SMC compression arching effect is higher than in OMC. Irregular pattern is noticed in connection 3 beams while in connection 4 the beams encountered axial compression force (Fig. 13).
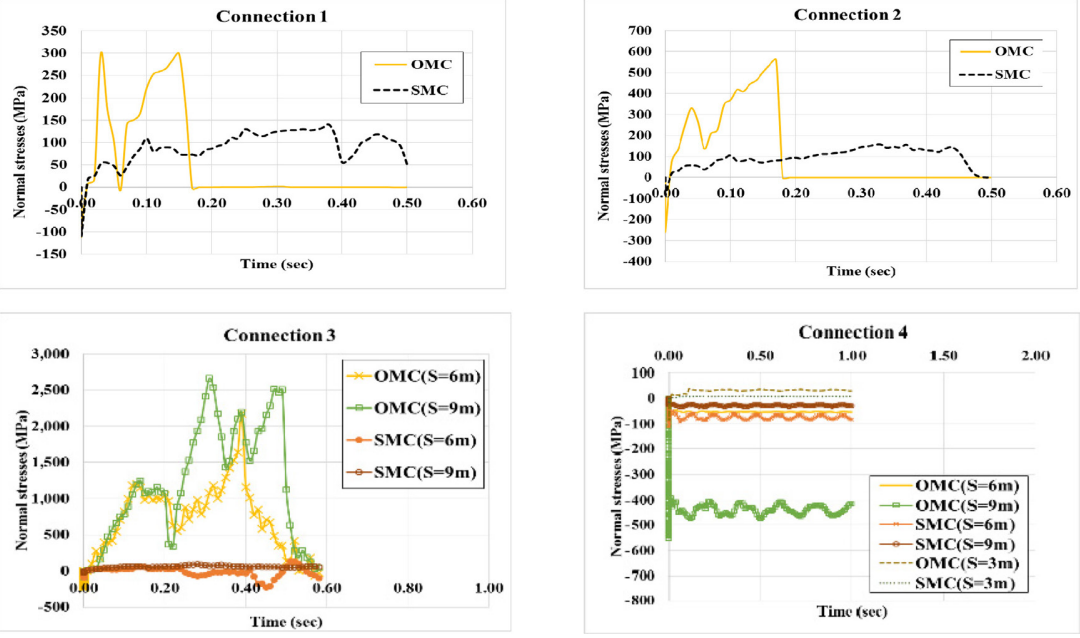

Figure 14: Dowels normal stresses versus time.
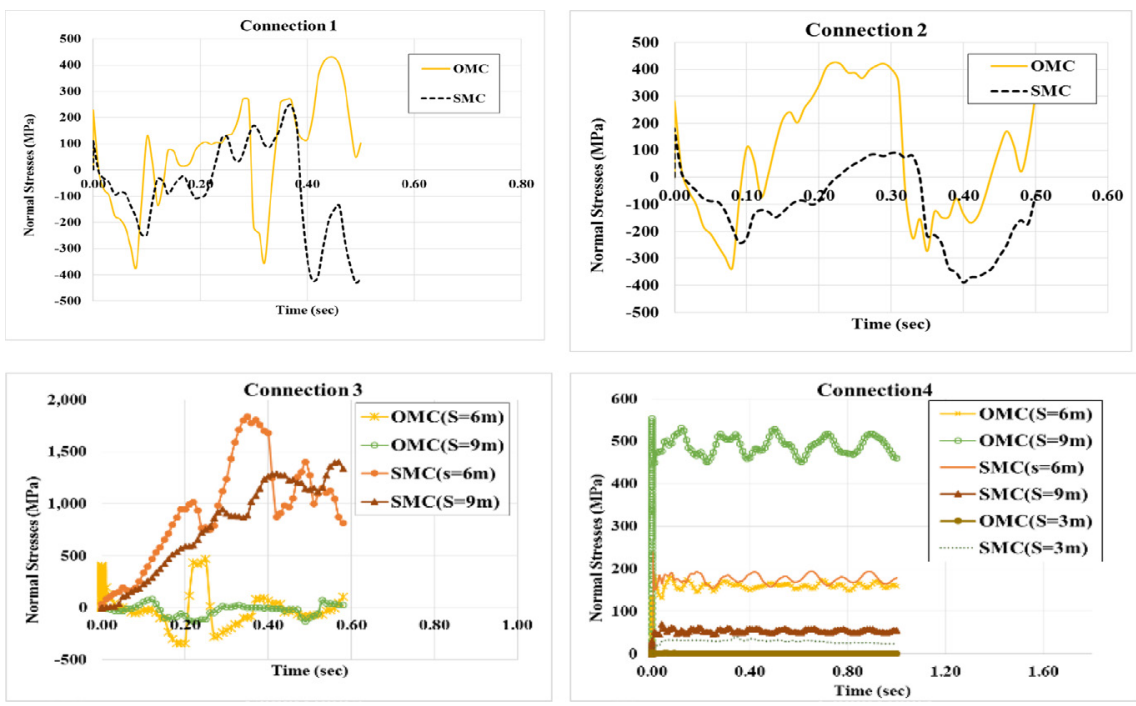

Figure 15: Top reinforcement normal stresses versus time. 

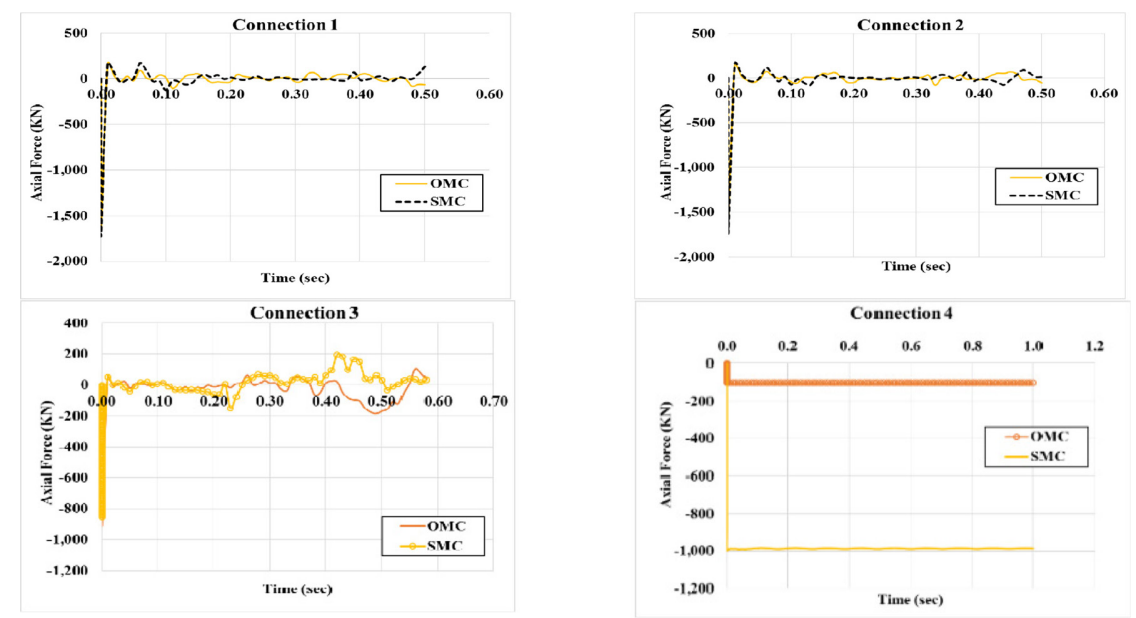

Figure 16: Axial column force versus time.

4.2.2.3 Reinforcement stresses. In OMC, dowels in connection 1, 2 and 3 encountered high tensile stresses than SMC. Dowels in OMC failed earlier than SMC at $0.18 \mathrm{sec}$ in connections 1 and 2, and at $0.58 \mathrm{sec}$ in 3 . For connection 4 dowels of $3 \mathrm{~m}$ span beam encountered tensile stresses of $34 \mathrm{MPa}$ while the dowels of the two other beams encountered compressive stresses of $470 \mathrm{MPa}$ in $9 \mathrm{~m}$ span beam (Fig. 14). Top Reinforcement of connection 1 and 2 in the OMC encountered compressive stresses at time $0.1 \mathrm{sec}$ of the column removal and after that it changed to tensile stresses while in SMC the compression stresses changed to tensile stresses at time $0.22 \mathrm{sec}$. Connection 3 reinforcement for both OMC and SMC encountered only tensile stresses. Connection 4 in SMC top reinforcement of both 6 and $9 \mathrm{~m}$ span beams encountered tensile stresses with negligible contribution of the $3 \mathrm{~m}$ span beam top reinforcement (Fig. 15).

4.2.2.4 Axial force in columns. Compression force is transformed to tension force in columns of connection 1 and 2 in both OMC and SMC (Fig. 16). Connection 3, both OMC and SMC, encountered axial tension force directly after the column removal, while connection 4 is not affected by the column removal in both OMC and SMC.

\section{CONCLUSION}

Applied Element Method was proven to efficiently analyze the precast connection subjected to column removal. It is found that the connection 4 in both OMC and SMC can resist the column removal scenario. This can be attributed to the perpendicular beams supporting the connection in the transverse, the top reinforcement with the contribution of the dowels of the out-of-plane played an important role in resisting the connection collapse. For connection 1, 2 and it is suggested to apply additional reinforcement extended from the column and embedded into the beams with a sufficient length to ensure that the column works as a tie in resisting failure due to progressive collapse. The importance of considering top reinforcement and dowels in the design against progressive collapse is highlighted. 


\section{REFERENCES}

[1] Shi, F., Assessment of progressive collapse requirements for precast concrete building, Lehigh University, 2011.

[2] Main, J.A., Bao, Y., Lew, H.S. \& Sadek, F., Robustness of Precast Concrete Frames: Experimental and Computational Studies, National Institute of Standards and Technology: Gaithersburg, 2014.

[3] Nimse, R.B., Josh, D.D. \& Patel, P.V., Experimental study on precast beam column connections constructed using RC corbel and steel billet under progressive collapse scenario. ASCE, no. Structures Congress, pp. 1011-1117, 2015. http://dx.doi.org/10.1061/9780784479117.094

[4] Nimse, R.B., Joshi, D.D. \& Patel, P.V., Behavior of wet precast beam column connections under progressive collapse scenario: an experimental study. International Journal of Advanced Structural Engineering, 6, pp. 149-159, 2014. http://dx.doi.org/10.1007/s40091-014-0072-3

[5] ACI COMMITTEE, 318, Building code requirements for structural concrete (ACI 31808) and commentary, American Concrete Institute, 2008.

[6] Meguro, K. \& Tagel-Din, H., AEM used for large displacement structure analysis. Journal of Natural Disaster Science, 24(1), pp. 25-342, 2003.

[7] Salem, H., El-Fouly, A. \& Tagel-Din, H., Toward an economic design of reinforced concrete structures against progressive collapse. Engineering Structures, 33(12), pp. 3341-3350, 2011. http://dx.doi.org/10.1016/j.engstruct.2011.06.020

[8] “www.appliedelementmethod.org," [Online].

[9] Tagel-Din, H. \& Megur, K., Applied element method for simulation of nonlinear materials: theory and application for RC structures in structural engineering. Earthquake Engineering Japan Society for Civil Engineers (JSCE), 17(2), pp. 137-148, 2000.

[10] Meguro, K. \& Tagel-Din, H., Applied element method for structural analysis : therory and application for linear materials in structural engineering. Earthquake Engineering, Japan Society for Civil Engineers (JSCE), 17(1), pp. 21-35, 2000.

[11] Meguro, K. \& Tagel-Din, H., Applied element simulation of RC structures under cyclic loading. American Society of Civil Engineering, 127(11), pp. 1295-1305, 2001. http://dx.doi.org/10.1061/(asce)0733-9445(2001)127:11(1295)

[12] Maekawa, K, \& Okamura, H., The deformational behavior and constitutive equation of concrete using the elasto-plastic and fracture model. Journal of Faculty of Engineering. University of Tokyo. Series B, 37(2), pp. 253-328, 1983.

[13] Ristic, D., Yamada, Y. \& Iemura, H., Stress-strain based modeling of hysteretic structures under earthquake induced bending and varying axial loads, Research report No. 86-ST-01, School of Civil Engineering, Kyoto University, 1986.

[14] Bathe, K., Solution of equilibrium equations in dynamic analysis. Englewoods Cliffs, NJ: Prentice Hall, 1982.

[15] Chopra, A., Dynamics of Structures: Theory and Applications to Earthquake Engineering, Prentice Hall: Englewoods Cliffs, N.J, 1995.

[16] PCI Industry Handbook Commitee, PCI design Handbook precast/prestressed Concrete, Chicago, Illinois: Prototype Type structure description, 2004.

[17] www.extremeloading.com Extreme Loading of Structure software Manual, [Online]. 